\title{
LUGONES Y EL MITO GAUCHESCO. UN CAPÍTULO DE HISTORIA CULTURAL ARGENTINA
}

\author{
A semejanza de aquellos extremos paladines \\ que para conservar más puro y vivo su amor \\ alejábanse del objeto amado, es, \\ precisamente, mi afección por el pueblo lo \\ que me impide acercarme a él. \\ LEOPOLDO LUGONES, \\ julio de 1915
}

En 1913, Leopoldo Lugones recibió una propuesta para pronunciar una serie de conferencias en el teatro Odeón de Buenos Aires. Su inmediata aceptación desembocó en seis lecturas que suscitaron las más encontradas reacciones en el público: desde la entusiasta aceptación por parte de su auditorio, hasta el total rechazo en círculos más amplios. El autor hizo algunas modificaciones a las seis lecturas originales, basadas en un trabajo iniciado en $\mathrm{Pa}$ rís en 1911, y añadió cuatro capítulos y un prólogo para publicar el conjunto en 1916 bajo el título de El payador ${ }^{1}$.

A primera vista, este texto provoca una sensación de heterogeneidad e incoherencia debido a la diversidad de materiales que lo componen: el análisis de la poesía épica y de su función en el mundo griego, la descripción de la música y la poesía gauchas, la reinterpretación de la historia argentina y, por último, el estudio dei Martín Fierro. Para diluir esta imagen, y empezar así a adscribir al conjunto una significación precisa, es necesario confrontarlo con el contexto cultural e histórico en que se inscribe.

Dos elementos del prólogo de la edición de 1916 orientan res-

${ }^{1}$ Leopoldo Lugones, "El payador" y antología de poesía y prosa, pról. de Jorge Luis Borges, selec., notas y cronología de Guillermo Ara, Biblioteca Ayacucho, Caracas, 1979. Todas las referencias al texto corresponden a esta edición. 
pecto del momento histórico y cultural en que se produce El payador. En primer lugar, el autor expresa que con este libro culmina una "obra particularmente argentina", iniciada doce años atrás, en la que se incluyen El imperio jesuitico (1904) y La guerra gaucha (1905); el primero de estos textos es un trabajo de carácter histórico sobre las misiones guaraníes organizadas por los jesuitas en el norte de Argentina durante la época colonial, mientras que el otro narra y ensalza la decisiva participación de la montonera gaucha de Güemes en el movimiento independentista. En segundo lugar, Lugones se congratula de que la publicación de El payador coincida con el centenario de la declaración de la independencia argentina. Sin duda, ambas expresiones - la intencionada búsqueda de temas " argentinos" y de una fecha ritual- denotan un esfuerzo muy consciente por incidir dentro de lo que en la cultura argentina se ha denominado "el espíritu del Centenario".

En efecto, en 1910, por iniciativa del Estado y con el apoyo de la clase dominante, se organizó en Argentina una serie de festejos para celebrar el centenario del inicio del movimiento independentista de 1810. Notables personajes extranjeros fueron invitados al país para que comprobaran en lo que éste se había convertido en su afán por modernizarse y ubicarse en un plano de igualdad con las sociedades capitalistas del mundo occidental; la imagen de Argentina como el cuerno de la abundancia e inacabable granero del mundo presidió los propósitos de la autofestejante oligarquía.

Pero la situación económica y social de la nación no era tan transparente y unívoca como algunos sectores de la clase en el poder querían hacer creer. Como veremos en detalle en el transcurso de este trabajo, las condiciones económicas y la estructura social del país se habían modificado drásticamente durante la segunda mitad del siglo XIX ${ }^{2}$. Ante la comprobación, en muchos casos dolorosa, de que vivían en un país que no se acoplaba a las expectativas heredadas de sus antepasados, los intelectuales ar-

${ }^{2}$ Aunque elaborada con mi personal perspectiva, la reconstrucción y síntesis de la historia argentina que aquí realizo se basa en los siguientes autores, a cuyos libros sólo remitiré en mi ensayo cuando los cite textualmente: JUAN E. Corradi, The fitful republic: economy, society, and politics in Argentina, Westview Press, Boulder, 1985; Tulo HalPerin DONGHI, Una nación para el desierto argentino, CEAL, Buenos Aires, 1982; José Luis Romero, El desarrollo de las ideas en la sociedad argentina del siglo XX, FCE, México, 1965 y Las ideas políticas en Argentina, FCE, México, 1946, y JAMEs R. SCOBIE, Argentina: a city and a nation, $2^{\text {a }}$ ed., Oxford University Press, Nueva York, 1971. 
gentinos reaccionaron de diversas maneras: "La más significativa de esas reacciones - por la larga repercusión de algunos de sus planteos, por el peso cultural de las figuras empeñadas en su difusión- fue la suscitada en torno al tema de la identidad nacional"'s.

Aunque esta búsqueda de identidad nacional es un tema omnipresente en los escritores argentinos de las primeras décadas de este siglo, no es exclusivo de Argentina sino más bien una tendencia cultural común a toda América Latina. En efecto, ante la comprobación de que los modelos sociales, políticos y económicos transplantados de Europa han sido ineficaces para la realidad americana, los pensadores latinoamericanos de diversas latitudes se empeñan en encontrar en su realidad modelos propios que suplanten a los caducos y ajenos: "After 1905 influential writers in both republics [Argentina y Chile] were rejecting the positivist and cosmopolitan-oriented ideologies invoked by the elites since the 1850 's to justify liberal immigration policies. In place of cosmopolitanism, these intellectuals began to formulate nationalistic ideologies [...]"'4. Estas tendencias nacionalistas propiciaron el surgimiento de los discursos de la "argentinidad", la "mexicanidad", etcétera, concomitantes en muchos casos de un concepto más amplio: el americanismo.

Si bien el nacionalismo es un fenómeno común a toda América Latina, no puede negarse su fuerte y especial incidencia en la cultura argentina. Tal vez la casi obsesiva presencia del tópico en ese país pueda explicarse por dos circunstancias: por la escasa integración social de Argentina y por tener ésta, más que ninguna otra nación latinoamericana, una proporción mayor de población de origen inmigratorio que no había compartido un pasado común; todo ello implicaba la carencia de identificaciones generales para los argentinos, y precisamente el nacionalismo pretendía crearlas.

Asistimos entonces a lo que en la historia cultural argentina se ha llamado "primer nacionalismo" o "nacionalismo cultural"; con esta última denominación se lo quiere diferenciar del "nacionalismo político" de ultraderecha de la década de 1930: eufemismo curioso que pretende enmascarar que lo cultural es también

3 Beatriz Sarlo y Carlos Altamirano, "La Argentina del Centenario: campo intelectual, vida literaria y temas ideológicos", en Ensayos argentinos. De Sarmiento a la vanguardia, CEAL, Buenos Aires, 1983, p. 72.

${ }^{4}$ Carl Solberg, Immigration and nationalism. Argentina and Chile, 1890-1914, University of Texas Press, Austin, 1970, p. 132. 
ideológico y, por tanto, político. Circunscrito temporalmente, este primer nacionalismo floreció en especial como correlato de los dos centenarios: el del inicio del movimiento de independencia de 1810 y el de la declaración de la independencia argentina en 1816.

Algunos de los más prominentes formadores de este nacionalismo fueron Ricardo Rojas, Leopoldo Lugones y Manuel Gálvez. Desde posiciones distintas, coincidentes en algunos puntos y contrapuestas en otros, ellos emprendieron en sus escritos la tarea de "encontrar" la identidad nacional, los rasgos esenciales del carácter argentino. Pero como la identidad nacional de un pueblo -en el supuesto de que ésta exista- no es un elemento eterno e inmutable previo a su historia política, económica y cultural, sino que se hace por medio de ella, estos escritores, más que "encontrar" esa identidad nacional, propusieron en sus textos una identidad nacional que, confrontada con la realidad social, informa sobre sus respectivas ideologías.

Desde esta perspectiva nacionalista del momento, nada tiene pues de excepcional que en el prólogo de El payador Lugones haga referencia a su obra "particularmente argentina" y se alegre de la contemporaneidad del texto con el centenario de la independencia. Por un lado, es una reflexión sobre la identidad argentina realizada a conciencia, con el deseo expreso de influir en el ámbito cultural; por el otro, supone la elección de una fecha ritual - la conmemoración del nacimiento de la patria - que legitime las propuestas nacionalistas del texto. En suma, se trata de una aspiración de trascendencia más allá de lo meramente literario.

Por tanto, en relación con la aparente incoherencia de $E l$ payador, puede decirse que su unidad reside en su tendencia hacia un objetivo único: la conformación de una identidad argentina específica. Así, por ejemplo, el mundo clásico de su obra, además de poderse interpretar como respuesta al acendrado hispanismo desarrollado por otros escritores nacionalistas (entre ellos Manuel Gálvez con su libro El solar de la raza, de 1913), se conjunta con la realidad argentina descrita en un proceso cuya finalidad es inventar raíces grecolatinas para la historia y la cultura argentinas.

Lugones estructura todo su texto alrededor de la primordial relación de interdependencia que establece entre el arte y la formación de un pueblo; así, expresa con claridad desde el prólogo:

Titulo este libro con el nombre de los antiguos cantores errantes que recorrían nuestras campañas trovando romances y endechas, por- 
que fueron ellos los personajes más significativos en la formación de nuestra raza. Tal cual ha pasado en todas las otras del tronco greco-latino, aquel fenómeno inicióse también aquí con una obra de belleza (p. 14).

Esta concepción del arte como entidad formativa de la nacionalidad se complementa con la exigencia lugoniana de que el arte debe tender hacia lo popular: "[ ... to todo grande arte social, como la epopeya, la ópera, la arquitectura pública, deben buscar los medios conducentes a la popularidad"' (p. 33). Se trata, naturalmente, de un pensamiento de hondas raíces románticas: Lugones reivindica lo popular porque cree que ahí residen las esencias de un pueblo, que por ende pueden rescatarse. Un claro ejemplo de este pensamiento romántico se percibe en su valoración de la música popular: "Los trozos de música popular argentina que van a continuación ofrecen ejemplos de todos los elementos mencionados en estas páginas. Son, por lo tanto, como toda música popular, cosa respetable para el pueblo cuya alma revelan; con lo cual quiero decir, que es menester conservarlos incólumes'" (p. 82; las cursivas son mías).

En efecto, la influencia del nacionalismo romántico europeo es discernible en el nacionalismo cultural argentino. En el conjunto de sus propuestas pueden encontrarse los tres aspectos básicos que conforman el nacionalismo de Herder ${ }^{5}$. En primer lugar, la creencia de que en toda nación hay un grupo originario (Volk) que constituye el más genuino y auténtico grupo de la sociedad. En segundo lugar, la idea de que este grupo posee una fuerza espiritual colectiva (Volkgeist) que provee ideales, es decir, lo que conforma el alma nacional. Por último, el convencimiento de que ese grupo originario, inspirado en el alma nacional, tiene que cumplir una misión cultural (Kulturauftrag).

Gon base en la citada idea lugoniana que asigna al arte una función tanto educativa como formadora de la nacionalidad, en el primer capítulo el autor intenta mostrar cómo en el mundo griego, que constituye su gran modelo cultural, la definición de la raza se produjo por medio de la poesía épica. ¿Cuál es el particular concepto de poesía épica manejado por Lugones en El payador?: "la poesía épica es la expresión de la vida heroica de una raza: de esa raza y no de otra alguna" (p. 29). Para él, el poema épico,

${ }^{5}$ Véase Earl T. Glauert, "Ricardo Rojas and the emergence of Argentine cultural nationalism", Hispanic American Historical Review, 43 (1963), 1-13. 
a diferencia del lírico, no canta a la libertad y a la justicia en abstracto, sino a la manera como cada pueblo ha luchado por estos ideales. La relación entre poema épico y nación se presenta entonces directa y transparente: ya que un poema épico expresa los rasgos diferenciales de un pueblo - su particular modo de luchar por los ideales de libertad y justicia-, la posesión de un poema épico implicará para un pueblo, automáticamente, la existencia de una identidad nacional.

Por ello desde el prólogo Lugones afirma que su objetivo central es comprobar que el poema de Hernández se inscribe dentro del género épico: "El objeto de este libro es, pues, definir bajo el mencionado aspecto la poesía épica, demostrar que nuestro Martín Fierro pertenece a ella, estudiarlo como tal, determinar simultáneamente, por la naturaleza de sus elementos, la formacion de esa raza, y con ello formular, por último, el secreto de su destino"' (p. 15).

La develación del "secreto" del destino de esa raza sólo es plausible por medio de la interpretación, la lectura, el desciframiento. De ahí que la estrategia implícita del texto consista, en el plano de la cultura argentina, en una doble legibilidad: primero, una reinterpretación de la historia argentina desde la conquista española hasta la época moderna y, segundo, una lectura distinta del Martín Fierro de José Hernández. Ambas fases están profundamente imbricadas y son interdependientes: para fundamentar el dato histórico se recurre al poema, así como para valorar éste se acude al refuerzo testimonial de la historia.

Como en cualquier otra historia cultural, los forjadores de este primer nacionalismo escriben contra y desde la perspectiva histórica heredada. Su visión de la historia argentina no puede prescindir de las categorías legadas por los intelectuales del siglo XIX. Por ello Lugones adopta la vieja dicotomía civilización y barbarie elaborada por Domingo Faustino Sarmiento para describir al país; sin embargo, del mismo modo que ha cambiado la estructura socioeconómica de Argentina, también se han desplazado los referentes concretos de ambos polos: los agentes de la civilización y de la barbarie en El payador no son los mismos que en el Facundo.

Lugones cree que la conquista española fue un fracaso absoluto en la pampa: "En este mar de hierba, indivisa comarca de tierras bravías, la conquista fracasó" (p. 36). Según su interpretación, la conquista fue incapaz de sumar a los indígenas a la civilización ("con la conquista su salvajez se hizo barbarie", dice) y más bien les proporcionó abundantes medios — ganado salvaje, 
poblaciones esparcidas y de escasa densidad donde era fácil realizar los malones - para persistir en sus hábitos; así, el indígena es descrito como absolutamente bárbaro e imposibilitado para participar de la civilización. Una de las críticas centrales del autor al indio es que una vez llegado éste a cierto punto de bienestar, hacía del ocio su felicidad suprema, "sin ningún estímulo personal de progreso" (p. 39); la perspectiva capitalista del juicio de Lugones es obvia en su incapacidad para comprender que en la primitiva economía indígena argentina el excedente en la producción de bienes no tiene sentido porque en esa cultura no existe necesidad de intercambio comercial.

En una posición diametralmente opuesta a la de Sarmiento, para quien el gaucho era parte de la barbarie, Lugones ubica a éste como contraparte de la barbarie indígena y le asigna una función básica en la pampa: "El gaucho fue el héroe y el civilizador de la pampa" (p. 36). A su juicio, el gaucho desempeñó un papel mediador entre los dos polos culturales: "Ahora bien, lo único que podía contener con eficacia a la barbarie, era un elemento que participando como ella de las ventajas locales, llevara el estímulo de la civilización. Y éste es el gaucho, producto pintoresco de aquel mismo conflicto" (p. 41).

Pero en su deseo por atribuir virtudes al gaucho, el autor no reconstruye históricamente la imagen de éste, sino que teje una leyenda a su alrededor. Dos son los métodos utilizados para la creación de este mito. Por un lado, la descripción del gaucho omite casi por completo las referencias concretas a las condiciones económico-sociales en que éste vivió, con lo que el gaucho parece más un ser mítico y ahistórico que real; así, por ejemplo, Lugones describe la especial labor ganadera del gaucho como una forma de diversión y de prueba de hombría y no como una determinante de su posición en el sistema social. Por otro lado, la escritura del autor está cargada de un exaltado lirismo por medio del cual el mundo del gaucho se presenta como un paraíso perdido:

Era de verlo por la pampa amarillenta, embebida al infinito en la tela del horizonte donde se hundía, recién volada de su laguna, la garza matinal, al galope del malacara o del obscuro cuyo ímpetu rebufaba, tascando generosos fervores en la roedura de la coscoja [...]. Empinado el sombrero ante las posibles alarmas del horizonte, y con ello más abierta la cara, el jinete iba sorbiendo aquel aire de la pampa que es - oh gloria de mi tierra - el aroma de la libertad (pp. 48-49). 
Su exaltación de la figura del gaucho no se detiene ahí. Dice Lugones que las condiciones del medio físico donde éste se desenvolvió - el dominio de la pampa, la lidia con el ganado bravío, el peligro de la "horda salvaje" - contribuyeron a cimentar en él "las mejores prendas humanas: serenidad, coraje, ingenio, meditación, sobriedad, vigor; todo eso hacía del gaucho un tipo de hombre libre, en quien se exaltaba, naturalmente, a romanticismo, la emoción de la eterna aventura"' (p. 42).

¿Qué finalidad tiene esta exaltación suprema del gaucho?: la de concebirlo como el fundamento de la "argentinidad". Lugones tiende un puente entre esta figura típica de la pampa argentina y el carácter del argentino de principios del siglo xx: "Si se recapitula [en] los elementos de este estudio, fácil será hallar en el gaucho el prototipo del argentino actual. Nuestras mejores prendas familiares [...] constituyen rasgos peculiares del tipo gaucho" (p. 50). Como se observa, el recurso retórico ("fácil será hallar") sirve para eludir la comprobación y presupone lo que tendría que demostrarse.

Así pues, en el discurso de El payador se valora hasta el extremo al gaucho por considerarlo como el elemento diferencial que conformó el carácter nacional argentino. Pero una vez propuesta la nutificación del gaucho, el texto se enfrenta a la insoslayable necesidad de explicar el innegable hecho histórico de su desaparición. ¿Cómo justificar que el gaucho, poseedor de tantas virtudes y esencia de la "argentinidad", haya desaparecido en el último tercio del siglo XIX?

La ambigüedad final que el autor asigna al gaucho responde este interrogante. El gaucho es el elemento civilizador de la pampa y posee los atributos máximos del carácter argentino, pero 'todo ello, por supuesto, en un estado primitivo, que oponía escasa resistencia al atavismo salvaje"' (p. 43). Según Lugones, el gaucho tenía dos rémoras inconciliables con la civilización: el ocio y el pesimismo heredados de sus antepasados, es decir, del indio y del español. Por ello, pese a su elogio del gaucho, el autor termina diciendo de él: "Su desaparición es un bien para el país, porque contenía un elemento inferior en su parte de sangre indígena" (p. 51).

En conclusión, en el sistema de valores de El payador, el gaucho es presentado con un carácter ambivalente que lo liga a ambos ejes de la dicotomía civilización-barbarie: civilizado en contraste con el indio en el ámbito de la pampa, pero bárbaro en última instancia para los fines de la civilización. Y aquí el concepto 
inmanente de civilización coincide puntualmente con el de los pensadores argentinos del siglo xIx: cuando en ambos casos se habla de civilización, se refiere implícitamente al proyecto oligárquico liberal de hacer de Argentina una nación moderna cuya economía se semeje a la de los países capitalistas occidentales; es decir, lo que en las tendencias liberales del siglo XIx y en las nacionalistas del xx se denomina civilización significa, en el fondo, modernización capitalista. El término de bárbaro aplicado tanto al indio como al gaucho implica la incapacidad de comprender una cultura distinta y, al mismo tiempo, califica la ineficacia de éstos para adaptarse a un nuevo sistema económico y social.

Con lo anterior, puede concluirse que el espectro de significaciones de la dicotomía civilización-barbarie se amplía en Lugones a tres ejes: en un extremo, el indígena bárbaro e irreductible a la civilización; en medio, el gaucho, quien participa de ambas connotaciones, y, en el otro extremo, la civilización para cuyo desarrollo era necesaria la desaparición de ambos. Sagazmente, la estrategia del discurso de El payador omite especificar quiénes fueron los agentes de la civilización causantes del exterminio de los indios y de la desaparición del gaucho. De hecho, la extinción de éste se describe en el texto como un fenómeno de selección natural, de evolución de la sociedad argentina hacia un estado superior: "No lamentemos, sin embargo, con exceso su desaparición. Producto de un medio atrasado, y oponiendo a la evolución civilizadora la remitencia [sic], o mejor dicho, la incapacidad nativa del indio antecesor, sólo la conservación de dicho estado habría favorecido su prosperidad" (o. 61; las cursivas son mías). En realidad, a través de todo El payador está presente una concepción histórica evolucionista: el "progreso", el paso de la sociedad hacia un estado superior, implica necesariamente la desaparición de los menos aptos, en este caso los gauchos.

En consonancia con los modelos clásicos que admira Lugones, la desaparición del gaucho no es sólo un hecho histórico irreversible, sino también una necesidad para su mitificación. Puesto que considera que la grandeza de una raza está además patente en sus heroicos orígenes, este mito preside una de las funciones del gaucho:

La guerra de independencia inició las calamidades del gaucho. Éste iba a pagar hasta extinguirse el inexorable tributo de muerte que la sumisión comporta, cimentando la nacionalidad con su sangre. He aquí el motivo de su redención en la historia, la razón de la sim- 
patía que nos inspira su sacrificio, no menos heroico por ser fatal (p. 60).

Se trata pues de un acto heroico que constituye a la vez un sacrificio ritual: un rito de sangre, de virilidad, que proveyó al carácter argentino de los atributos y de la fuerza indispensables para aspirar a un destino de grandeza. Consumado el sacrificio ritual de los orígenes de la identidad argentina, petrificado ya el gaucho en un mito que lo sublima, el autor lo despide con una evocación lírica citada con frecuencia:

El gaucho aceptó su derrota con el reservado pesimismo de la altivez. Ya no necesitaba de él la patria injusta, y entonces se fue el generoso. Herido al alma, ahogó varonilmente su gemido en canciones. Dijérase que lo hemos visto desaparecer tras los collados familiares, al tranco de su caballo, despacito, porque no vayan a creer que es de miedo, con la última tarde que iba pardeando como el ala de la torcaz, bajo el chambergo lóbrego y el poncho pendiente de los hombros en decaídos pliegues de bandera a media asta (p. 62).

Debido a la desaparición real del gaucho, Lugones plantea el espacio literario como el medio para su recuperación: el símbolo de las más altas virtudes del carácter argentino no existe ya, pero ha quedado plasmado en la literatura: "Es también la hora de su justificación en el estudio del poema que lo ha inmortalizado" (p. 60). Así, el Martín Fierro resulta el instrumento para comprobar las excelencias de la identidad argentina. De este modo, con su estudio del poema de Hernández, Lugones se alínea en uno de los temas más recurrentes del nacionalismo argentino:

Estas tendencias hallarán una cristalización característica (y de larga influencia en la cultura argentina) en el movimiento de revaloración del Martín Fierro, que tuvo su punto de condensación en el año 1913. La nueva lectura del poema de Hernández no sólo fue ocasión para la transfiguración mitológica del gaucho - convertido en arquetipo de la raza-, sino también para establecer el texto "fundador" de la nacionalidad ${ }^{6}$.

La conclusión es lógica: si las características de la identidad nacional están cifradas en el Martín Fierro, entonces éste es el texto fundador de la nacionalidad. Por ello, lo importante para el

${ }^{6}$ B. Sarlo y C. Altamirano, op. cit., p. 98. 
autor es definir el poema de Hernández como poesía épica con base en la lucha del gaucho por la libertad y, a partir de éste, identificar los rasgos esenciales de la "argentinidad"; lo demás es ancilar y secundario; de ahí su análisis fragmentario, parcial, dirigido, del Martín Fierro. Creo que, en general, la interpretación que Lugones hace del poema gauchesco peca de los defectos inherentes a su orientación, puesto que muchos de los rasgos estilísticos que hacen de este texto una gran obra de arte escapan a su percepción por ubicarse fuera de su limitada óptica.

No obstante su perspectiva, el autor acierta al ver la segunda parte del poema como inferior a la primera. A este respecto, dice que en La vuelta Hernández se dejó influir por la crítica culta y atendió a varias de las censuras que se le habían hecho: "Hizo literatura de precepto y de epíteto, falseando la propiedad de expresión que es el mérito fundamental de sus personajes" (p. 173). En efecto, creo que lo que Lugones llama "propiedad de expresión" constituye uno de los elementos más valiosos, o acaso el más valioso, del Martín Fierro: una excelente adecuación literaria de la lengua utilizada por los gauchos en la pampa; es decir, se trata de una escritura que trabaja con la oralidad.

Las virtudes que Lugones había adscrito al gaucho en su reinterpretación de la historia argentina aparecen confirmadas en su lectura del poema de Hernández: así, el personaje central es un héroe o paladín, como él lo llama, cuyas excelsas virtudes lo hacen luchar por la libertad y la justicia; aunque ciertamente no se precisa con exactitud, en la lectura de Lugones, el momento histórico de esta lucha. Si bien la elaboración completa del mito del gaucho como base de la identidad argentina se efectúa en la época de la que venimos hablando, Lugones había sido antecedido por otros escritores en una visión del gaucho separada de su realidad económica y social; por ejemplo, en 1902 Ernesto Quesada describía al gaucho en estos términos: "nació filósofo, desengañado de las vanidades del mundo, contento de antemano con su suerte, cualquiera que ésta sea"'7. Pero la distancia que media entre las respectivas imágenes del gaucho de Quesada y de Lugones es la que existe entre una simple evocación nostálgica y la proposición de un mito de identificación colectiva, de un símbolo nacional.

${ }^{7}$ ERnesto Quesada, “El criollismo en la literatura argentina”, en En torno al criollismo, comp. Alfredo V. E. Rubione, CEAL, Buenos Aires, 1983, p. 215. 
Si para los intelectuales del siglo xıx el gaucho, el desierto y la carreta representaban la barbarie que había que superar en la marcha hacia el progreso, para los nacionalistas del Centenario estos mismos elementos se transforman en los símbolos de una "tradición nacional" que el progreso amenaza con disolver. Así, la mitificación del gaucho que Lugones efectúa pertenece a esta "nueva" tradición nacional; y precisamente por ser "nueva", puede decirse que es una tradición inventada:

There is probably no time and place with which historians are concerned which has not seen the "invention" of traditions. However, we should expect it to occur more frequently when a rapid transformation of society weakens or destroys the social patterns for which "old" traditions have been designed, producing new ones to which they were not applicable, or when such old traditions and their institutional carriers and promulgators no longer prove sufficiently adaptable and flexible, or are otherwise eliminated: in short, when there are sufficiently large and rapid changes on the demand or the supply side $^{8}$.

¿Cómo había ocurrido esa rápida transformación de la sociedad argentina que hizo caducar los modelos decimonónicos? : con los resultados del proyecto liberal de desarrollo puesto en práctica por la oligarquía durante ia segunda mitad del siglo diecinueve.

Luego de la caída de Rosas en 1852, empezó a aplicarse un modelo de desarrollo económico y social basado en el pensamiento liberal y sustentado por la oligarquía. Los constructores del Estado nacional - Alberdi, Sarmiento, Mitre - habían percibido, muy sagazmente, que el ámbito internacional se caracterizaba en lo económico por la expansión del centro capitalista hacia la periferia, por lo que se propusieron acelerar y aprovechar este proceso; los medios concebidos para conformar la estructura capitalista exportadora deseada por la oligarquía fueron los capitales extranjeros, en especial ingleses, y la fuerza de trabajo de las masas inmigratorias, a las que se consideraba instrumento indispensable para la civilización y el progreso. Sin embargo, debido a la previa división internacional del trabajo, el proyecto llevó a Argentina a constituirse en exportador de materias primas - carnes,

${ }^{8}$ Eric Hobsbawm, "Introduction: inventing traditions", en The invention of traditions, eds. E. Hobsbawm y Terence Ranger, Cambridge University Press, Londres, 1983, pp. 4-5. 
cereales y lana- e importador de bienes manufacturados; así, a partir de la década de 1860 la economía argentina empezó a sufrir ciclos de auge y depresión económica dependiendo de la demanda y precio de sus materias de exportación. Es decir, en Argentina se asentaron también las restricciones de otros sistemas periféricos y dependientes de América Latina.

En su afán exportador, el liberalismo económico propició el desarrollo de ciertas regiones de Argentina en detrimento de otras. Así, hacia 1910 el país se hallaba inmerso en múltiples contradicciones económicas y sociales manifiestas en sus dos bien diferenciadas facetas: al lado de la nación moderna representada por Buenos Aires y el litoral —con ciudades cosmopolitas, trenes, fábricas, etcétera - había también la Argentina del interior, eminentemente rural y estancada en su economía; en lo social, se presentaba una lucha de clases motivada por las profundas disparidades en la distribución de la riqueza y acentuada por la diversidad étnica producto de la inmigración; esta lucha social se expresaba en un creciente número de huelgas laborales y en movimientos anarquistas y socialistas que amenazaban con socavar los cimientos del Estado. En suma, el proyecto oligárquico había fracasado en su deseo de sustentar un desarrollo armónico: no había podido resolver la contradicción esencial existente entre una doctrina liberal en lo económico y estatal, y profundamente conservadora en el plano social y político.

Respecto del gaucho, el proyecto liberal tuvo un gran impacto sobre la identidad social de éste. Como grupo social identificable, los gauchos se caracterizaban por ser jinetes migratorios y trabajadores rurales habituados a una vida de frontera; ejercían su libertad estableciendo su hogar en cualquier lugar de la pampa y cazando indiscriminadamente ganado salvaje, el cual se había multiplicado con profusión gracias a los primeros ejemplares abandonados en la pampa por los españoles; ocasionalmente, el gaucho se contrataba en alguna estancia para las labores ganaderas de la temporada. Las necesidades del naciente capitalismo exportador argentino valorizaron con rapidez la tierra y el ganado, por lo que los sucesivos gobiernos defendieron los intereses de la élite terrateniente mediante nuevos derechos legales y un nuevo concepto de propiedad privada que le permitieron apropiarse de todas las tierras utilizables y del antes ganado salvaje. Con ello el gaucho quedaba reducido, en el mejor de los casos, a permanente peón de estancia, ya que las nacientes labores agrícolas le eran desconocidas. Así quedaban canceladas para siempre las po- 
sibilidades de ese ser nómada que antes vagaba con libertad por la pampa.

De hecho, Lugones no hace en El payador referencias explícitas al proceso mediante el cual desapareció el gaucho, ese símbolo de la "argentinidad". Como veremos, su silencio, o más bien su ocultamiento, es parte de la finalidad última de su obra.

Al revisar la crítica que hasta entonces había recibido el Martín Fierro, Lugones observa que mientras las mayorías reconocieron de inmediato su grandeza, las élites cultas lo rechazaron con menosprecio 9 . Por ello plantea su lectura como un momento de reivindicación: un acto de justicia y una labor de rescate cuya finalidad expresa es que las élites hagan también suyo el poema; así se percibe en las palabras que leyó después de su última conferencia en 1913: "Felicítome por haber sido el agente de una íntima comunicación nacional entre la poesía del pueblo y la mente culta de la clase superior; que así es como se forma el espíritu de la patria"' (p. 201).

Los destinatarios de su discurso se perfilan entonces con nitidez absoluta: El payador está dirigido a la "clase superior", no a todos los estratos que conforman la sociedad argentina. Pero resulta que esa "clase superior", con su acción dirigente, causó la desaparición del gaucho. En su texto, Lugones cree resolver esta contradicción velando la identidad de los agentes de la civilización en su lectura de la historia argentina. Consecuente con ello, el autor elude una verdadera evaluación del pasado y más bien tiende a construir una apología del presente:

No obstante, aquella oligarquía tuvo la inteligencia y el patriotismo de preparar la democracia contra su propio interés, comprendiendo que iba en ello la grandeza futura de la nación. Así supo constituir por esfuerzo enteramente propio, con individuos exclusivamente suyos, los fundamentos de la sociedad democrática: la instrucción pública, la inmigración europea, el fomento de la riqueza y la legislación laboral. Los resultados están a la vista (p. 54).

Finaliza Lugones el párrafo anterior con un giro retórico que ya le hemos visto utilizar para eludir las comprobaciones. De acuerdo con su apología, la clase oligárquica aparece como un grupo homogéneo cuya función "patriótica" la lleva a actuar exclusi-

${ }^{9}$ Interesantes datos sobre la recepción contemporánea del Martín Fierro los encontramos en: María Teresa Gramuglio y Beatriz Sarlo, "José Hernández", en La literatura gauchesca, CEAL, Buenos Aires, 1985. 
vamente en aras de la grandeza del país e incluso en contra de sus propios intereses. Nada más falso.

Para comenzar, el proyecto de la oligarquía no era, en ningún sentido, un proyecto "nacional". Al igual que en varios de los nuevos Estados latinoamericanos, lo que se investía con el carácter de lo "nacional" era en realidad un proyecto clasista cuyo propósito consistía en aumentar la riqueza de la oligarquía por medio de la exportación de productos agropecuarios. Durante la primera mitad del siglo XIx, la élite terrateniente sólo recibía limitados ingresos de sus extensas posesiones debido al incipiente desarrollo de la economía. La inversión de capital extranjero y la mano de obra de las masas inmigradas, a la que se sumó la de la clase nativa desposeída, convirtieron esas tierras en lucrativos bienes de producción, usufructuados, naturalmente, por la oligarquía.

Además, los "fundamentos de la sociedad democrática" de que habla Lugones no fueron producto del patriotismo de la oligarquía, sino resultado de la lucha de clases existente en el seno de la sociedad argentina. Históricamente, el proyecto liberal se había puesto en marcha con la absoluta prescindencia del consenso popular; para los intelectuales del siglo XIX, pertenecientes a la oligarquía, las masas constituían más un elemento maleable que una voluntad activa. Por ello, ante la imposición de un modelo totalmente ajeno a su cultura, las masas asumieron una actitud negativa, de rechazo, ya que en principio ellas mismas no podían elaborar y proponer un modelo alterno propio expresado en los términos de la cultura letrada:

A medida que el conglomerado se fue decantando - muy lentamente- sus tendencias políticas comenzaron a perfilarse. En rigor sólo los elementos negativos se insinuaron con nitidez; la masa que se plasmaba se manifestó, por reacción contra la élite, antioligárquica, antiliberal, refractaria a la civilización europea; poco después afirmó su enérgico impulso democrático y acentuó su tono popular hasta sobrestimar lo que la élite menospreciaba. Y, frente a la resistencia de la clase que detentaba el poder, se fue perfilando una actitud política de renovación orientada hacia la democracia ${ }^{10}$.

Llevada hasta sus consecuencias en todos los planos, la teoría liberal hubiera desembocado en la democracia. Sin embargo, la

${ }^{10}$ José Luis Romero, Las ideas políticas..., p. 183. 
oligarquía mantuvo un férreo control del aparato gubernamental. Así, pese a la presión política de las masas y a las fisuras muy evidentes en el seno de la oligarquía entre reformistas y tradicionalistas, ésta aún detentaba el poder político hacia 1913. No sorprende pues que la apología de Lugones haya recibido un decidido apoyo por parte de la clase gobernante. Tampoco resultó casual que el auditorio de las conferencias lugonianas, compuesto por prominentes miembros de la oligarquía y encabezado por el propio presidente de la República, aplaudiera sin límites la visión del autor:

Ahí estaban los destinatarios del mensaje, el mito gaucho; el poetamedium, al resucitar la verdad primordial de los "tiempos heroicos" la transmite a sus verdaderos titulares: la clase superior. El escritor "forma el espíritu de la patria" forjando mitos de legitimación para los que gobiernan ${ }^{11}$.

Con su discurso Lugones asume pues una función social específica: la de creador de mitos que confieren la legitimidad del poder a un particular grupo social. En su trasfondo ideológico, el texto de Lugones es un intento por revivir una situación derruida en la década de 1880 . Antes de esa fecha, el escritor se identificaba con su grupo social, al cual a la vez veía como la representación auténtica de la nación; es decir, la conciencia de la cla* se dominante, a la cual pertenecía el escritor, equivalía a la nacionalidad. La figura de Sarmiento, intelectual y estadista, escritor y presidente, marca el apogeo de un proceso irrepetible en la Argentina de principios del siglo xx debido a la diferenciación de funciones en los distintos campos: el gentleman-escritor ${ }^{12}$, que había sucedido a los intelectuales estadistas, desaparece y en su lugar surge un escritor que asume su oficio como una profesión perfectamente diferenciada.

Un signo de esta profesionalización del oficio de escritor es el concepto y conciencia de estilo que tiene Lugones, quien al terminar su exposición, dice: "Así se cumple con la civilización y la patria. Movilizando ideas y expresiones, no escribiendo sistemáticamente en gaucho'" (p. 197). Hay una clara asociación entre función social y estilo: Lugones desecha la lengua gaucha del

11 B. Sarlo y C. Altamirano, op. cit., p. 102.

12 Para una descripción detallada de este proceso, véase David Viñas, $L i$ teratura argentina y realidad política, CEAL, Buenos Aires, 1982. 
Martín Fierro porque ésta resulta inadecuada para la nueva función que él ha asignado al gaucho. Como el propósito de este trabajo no es analizar en detalle la lengua de El payador, baste con mencionar que el autor abandona aquí la insufrible e ilegible prosa de La guerra gaucha - sólo descifrable con el auxilio de un diccionario debido a sus excesos regionalistas y arcaicos, por lo que requirió incluso un glosario al final del texto- e inventa un nuevo lenguaje que, aunque con resabios modernistas, se convertirá en modelo de escritura para la época ${ }^{13}$.

Si bien la confluencia entre conciencia de clase y nacionalidad no existe más, es cierto que el escritor sigue adquiriendo su identidad social, aunque no siempre sus medios de subsistencia, por medio de la literatura. El aislamiento social del escritor y la incomprensión de su público, quejas de las que el modernismo hizo tópicos literarios, quedan superados cuando el escritor asume una nueva función social: "Pero la década del Centenario, de 1910, prometió revertir esta tendencia, integrando al escritor en el servicio de una historia nacional, como se había hecho durante el siglo anterior" 14 .

Quizá sea más preciso decir que en esta época el escritor se sumó más bien a la elaboración de una historia nacionalista y no "nacional". Esto se observa muy bien en el discurso nacionalista de El payador, signado por una marcada tendencia clasista. Hay una insoluble contradicción entre el mensaje y los destinatarios del texto: por un lado, se propone al gaucho como un mito de identificación colectiva, pero, por otro, este mensaje está dirigido única y exclusivamente a la "clase superior". Lo que en realidad sucede es que el gaucho, ineficaz para los fines capitalistas de la oligarquía en el siglo XIX, es usado a principios del xx como instrumento de oposición a la naciente fuerza de la masa inmigratoria:

La oligarquía resucitó al largamente vilipendiado y rebelde gaucho y lo transformó en un símbolo nostálgico idealizado de virtudes na-

13 Si por un lado el rechazo de Lugones a la "fraseología gauchesca" significa un distanciamiento respecto del trabajo con la oralidad típico de la literatura gauchesca, por el otro implica un repudio a ese cúmulo de obras populares difundidas bajo el nombre genérico de "literatura criolla", las cuales habían asimilado ya muchas de las características propias de la literatura gauchesca. Sobre este último aspecto, véase AdOLFo PRIETO, El discurso criollista en la formación de la Argentina moderna, Sudamericana, Buenos Aires, 1988.

${ }^{14}$ Francine Masiello, Lenguaje e ideología. Las escuelas argentinas de vanguardia, Hachette, Buenos Aires, 1986, p. 33. 
tivas y de patriotismo. Irónicamente, el gaucho, tan despreciado por la élite terrateniente, se convirtió en el arma ideológica central de la lucha de la élite contra las exigencias de justicia social y de democracia de los trabajadores inmigrantes. Durante el siglo xx, los nacionalistas conservadores promovieron al gaucho como símbolo de $\operatorname{argentinidad}^{15}$.

Aunque en la realidad histórica el gaucho haya sido un ser social marginado, poseía características que lo hacían susceptible de convertirse en instrumento del nacionalismo. En primer lugar, el gaucho, independientemente de su posición social, era una figura autóctona, vernácula, típicamente argentina. Además, aunque en su momento él había sido un rebelde a los designios de la oligarquía, hacia 1910 no era más que un "héroe muerto" pasible de cualquier deformación. Por último, el gaucho remitía a un pasado argentino previo a la inmigración masiva. Todos estos factores posibilitaron que la oligarquía utilizara al gaucho para descalificar a la población de origen inmigratorio y legitimar, al mismo tiempo, su permanencia en el poder.

Al ubicar la esencia de la "argentinidad" en un pasado preinmigratorio, al no sumar ninguna de las características de los inmigrantes al acervo del ser nacional, Lugones expresaba en verdad un fuerte rechazo a las masas. Naturalmente, fuera de los círculos asociados a la oligarquía, la propuesta de Lugones tenía que provocar reacciones negativas.

Dentro de esta corriente, la revista Nosotros organizó en 1913 una encuesta entre los intelectuales argentinos para establecer el valor real del Martín Fierro ${ }^{16}$. La dirección de la revista, ejercida por dos intelectuales de origen inmigratorio, Giusti y Bianchi, se siente motivada a realizar esta encuesta tanto por las opiniones de Lugones en El payador como por las ideas expuestas por Ricardo Rojas al inaugurar su Cátedra de Literatura Argentina en 1912. La publicación plantea un doble interrogante:

¿Poseemos en efecto un poema nacional, en cuyas estrofas resuena la voz de la raza? [. . . . ¿Es el poema de Hernández una obra ge-

${ }^{15}$ Richard W. Slatta, "El gaucho argentino", trad. Graziella Baravalle, en Marginados, fronterizos, rebeldes y oprimidos, comp. Miquel Izard, Eds. del Serbal, Barcelona, 1985, t. 2, pp. 98-99.

16 “ ¿Cuál es el valor de Martín Fierro?”, Nosotros, 1913, núm. 50, 425-433; 1913, núm. 51, 74-89; 1913, núm. 52, 186-190, y 1913, núm. 54, 59-74. 
nial, de las que desafían los siglos, o estamos por ventura creando una bella ficción, para satisfacción de nuestro patriotismo? ${ }^{17}$

Los comentarios de quienes respondieron a la encuesta se inclinan a discurrir respecto de una o de ambas vertientes: la definición del Martín Fierro en cuanto poema épico de valor universal y/o su aceptación como símbolo de la raza argentina.

Algunos de los intelectuales más conocidos - Manuel Ugarte, Martiniano Leguizamón y Manuel Gálvez - coincidieron con la interpretación de Lugones y por tanto aceptaron al Martín Fierro a la vez como la cima de la literatura argentina y como la encarnación del espíritu nacional. Desde una perspectiva exclusivamente literaria y universalista, en cambio, Hugo de Achával y Emilio Lazcano Tegui se negaron a reconocer en el poema de Hernández una obra de valor universal equiparable, por ejemplo, a la Chanson de Roland.

Un profesor universitario, Rodolfo Rivarola, señala con acierto que el Martín Fierro no podía ser el poema nacional porque la "raza criolla" para la cual había sido escrito y de la cual había surgido no existía más. Por ello el poema de Hernández, afirma, sólo podía ser apreciado en ese momento por lo que tuviera de humano y no de "nacional".

Pero la crítica más acerba de esta encuesta provino del socialista Antonio de Tomaso. Aunque éste acepta las excelencias del poema, le niega estatus de obra "nacional" porque, a su juicio, en él no se reconoce la Argentina de entonces, y además afirma que el "tipo étnico" propio del país apenas se está elaborando. Asimismo, se muestra sorprendido de que quienes pretendían hacer del Martín Fierro un poema nacional fueran los mismos que antes habían cantado cosas "realmente exóticas": princesas, duquesas, abates, Versalles, delirios parisinos, falsas ensoñaciones griegas, etcétera. Finaliza diciendo que con la propuesta nacionalista sólo se estaba creando una ficción para satisfacer vanamente el patriotismo.

Fuera de esta encuesta de la revista Nosotros, algunos escritores socialistas, con una aguda visión del momento político y social, atacaron el nacionalismo cultural - tanto el de Lugones como el de los otros nacionalistas - por considerarlo nacionalismo de clase; aseguraban que la clase alta promovía reverencia hacia valores que justificaban su continuo control político. Precisamente

${ }^{17}$ Ibid., núm. 50, p. 425. 
el fundador del partido socialista, Juan Bautista Justo, en su obra La teoría cientifica de la historia y la política argentina (1898), había definido a los gauchos, de un modo diametralmente opuesto al de Lugones, como "la población de los campos acorralada y desalojada por la producción capitalista, a la que era incapaz de adaptarse, que se alzaba contra los propietarios del suelo, cada vez más ávidos de tierra y de ganancias", 18 .

Dentro de esa misma línea interpretativa del gaucho, así como del poema de Hernández, había trabajado el intelectual anarquista Alberto Ghiraldo. Luchador incansable en la defensa de los derechos de las clases desposeídas, había fundado en marzo de 1904 una revista semanal con el nombre de Martín Fierro, la cual al año siguiente pasó a ser un suplemento del combativo periódico La protesta. El anarquista Ghiraldo se identifica personalmente con la actitud rebelde del protagonista de Hernández y a la vez quiere aprovechar la popularidad del poema para llegar al pueblo con la verdad y la belleza, haciendo comprender "a los pobres, a los humildes, a los tristes que ambulan llevando odios y rencores por las injusticias, que una nueva aurora luce su esplendor en el horizonte" 19 . Es pues, a todas luces, un uso del nombre del Martín Fierro con un profundo sentido de lucha social, de reivindicación de las masas, que está muy alejado de los intereses de los nacionalistas.

El rechazo de ciertos sectores de la sociedad argentina a la mitificación del gaucho plantea el interrogante de explicar cómo pudo esa figura convertirse finalmente en un símbolo nacional. Aunque responder cabalmente esta pregunta implicaría la revisión de toda la historia cultural argentina de este siglo, cabe aventurar alguna explicación, por limitada que sea.

Ya en 1902, en un texto citado aquí respecto de la evocación nostálgica del gaucho, Ernesto Quesada se quejaba amargamente de que, en las fiestas populares, la población de origen inmigratorio manifestara una empeñosa persistencia en vestirse a la usanza e imitar las costumbres gauchas. Esa actitud mimética de la masa inmigratoria demuestra que ésta llenaba su necesidad sicológica de identificación con su nuevo país por medio del gaucho, esa figura que ellos percibían como pintoresca en muchas ocasiones, pero que sin duda era una figura autóctona:

${ }^{18}$ Apud José Luis Romero, El desarrollo de las ideas..., p. 64.

19 A. GHiraldo, apud Héctor Adolfo Cordero, Alberto Ghiraldo, precursor de nuevos tiempos, Claridad, Buenos Aires, 1962, p. 86. 
Ironically, however, the children of these immigrants, who dreamed so longingly of Europe, violently rejected the European connections. Although citizens by the factor of their birth in Argentina, psychologically they needed to assert their "Argentinism". They consequently sought to shed all traits which could link them to the foreign land ${ }^{20}$.

En el espacio literario, una muestra de esta actitud es el libro de relatos Los gauchos judíos (1910), en cuyo título, casi un oxímoron, se resume el anhelo de su autor, el judío argentino Alberto Gerchunoff, por celebrar el Centenario mediante una simbiosis de las culturas gaucha y judía. Para Gerchunoff, el Centenario sirve también como medio de legitimación, pero en un sentido inverso: su propósito es demostrar cómo la colonia judía de Entre Ríos, originaria de Rusia, se está asimilando a la nación que la adoptó; así, el autor celebra las fiestas del centenario de la independencia como cualquier verdadero argentino, negando de facto la ajenidad endilgada a los inmigrantes.

En la década del Centenario, la búsqueda de identidad de los inmigrantes coincidió con su rechazo a definir lo argentino sólo con elementos preinmigratorios. En última instancia, la masa inmigratoria pretendía cierto acercamiento con lo argentino por medio del gaucho, pero repudiaba la constitución de la identidad nacional usando única y exclusivamente las características de éste.

La airada respuesta de Lugones a los detractores de su mitificación del gaucho no se percibe directamente en el texto de $E l$ payador, sino en el prólogo de la edición de 1916. Allí, con un gesto soberbio, el autor descalifica a quienes rechazan sus ideas: "La plebe ultramarina, que a semejanza de los mendigos ingratos nos armaba escándalo en el zaguán, desató contra mí al instante sus cómplices mulatos y sus sectarios mestizos'" (p. 15). La ideología de Lugones se muestra en esta cita con transparencia. Define a la sociedad argentina con dos pronombres: "nosotros" y "ellos". Del lado del "nosotros" están todos aquellos que no son inmigrantes ni poseen rasgos de mestizaje, es decir, los criollos puros, quienes aparecen como dueños legítimos del país; los "otros" son los inmigrantes, apoyados por los mestizos, a quienes se considera advenedizos en la sociedad argentina.

La postura de rechazo a la inmigración expresada por Lugones en 1916 difiere de la que había dibujado en 1910 en su "Oda

${ }^{20}$ James R. Scobie, op. cit., p. 134. 
a los ganados y a las mieses', de Odas seculares. Allí, con una poesía lírica de corte modernista, Lugones entona un canto a la grandeza argentina y alaba los verdes campos de trigo y la blonda juventud europea que los cultivaba ${ }^{21}$. Pero la situación urbana en 1916 es muy diferente de la campirana en 1910. En Buenos Aires el obrero, de origen inmigratorio, se percibe como amenazante; allí el trabajador no está inerme sino que lucha por sus intereses económicos y sociales:

Long accustomed to servile laborers, the Argentine ruling classes after 1890 suddenly had to confront militant urban workers determined to improve their economic position. Most skilled workers entered socialist-oriented unions, but the anarchists, who controlled much of Buenos Aires' unskilled laboring class, quickly became the most powerful element in the Argentine labor movement ${ }^{22}$.

Mientras en 1910 Lugones cantaba al campo argentino, la ciudad de Buenos Aires experimentaba violentos conflictos sociales. Guando el gobierno argentino se dispuso a organizar los festejos del Centenario, el movimiento anarquista, exasperado por la represión de que había sido víctima en 1909, amenazó con una huelga general durante la celebración. La reacción del Estado fue inmediata y contundente. El 14 de mayo, las dos cámaras declararon el estado de sitio y la policía, auxiliada por una milicia ciudadana de la clase alta, saqueó y quemó las oficinas y órganos difusores

${ }^{21}$ Ciertamente, durante este periodo se generalizó la tendencia a escribir poesía laudatoria del Centenario (el mismo Rubén Darío, pese a no ser argentino, se sumó a los ditirambos); sin embargo, en el propio título de la oda lugoniana pueden percibirse ya las inclinaciones ideológicas del autor: al alabar la grandeza de la patria, el poeta canta "a los ganados y a las mieses", es decir, a los productos y no a los productores, a los objetos y no a los sujetos. Muy distante en el tono, en cambio, resulta la contemporánea "Oda a los padres de la patria" de ENRIQue Banchs (Nosotros, 1911, núm. 27, 30-42); mientras Rojas y Lugones consideran que los grandes próceres son los padres de la patria (hecho patente en sus respectivas biografías sobre San Martín y Sarmiento), Banchs entona un cántico a todos esos héroes anónimos que poblaron la pampa y empezaron a engrandecerla: el cartero que llevaba las noticias, los pioneros del alambrado y la agricultura, los constructores de los caminos de hierro, etcétera; lástima que la encomiable "buena intención" de Banchs no haya tenido su correspondencia en el plano de la expresión artística: su larga oda en endecasílabos rimados resulta farragosa y de lectura aburrida en muchos pasajes.

${ }^{22}$ C. Solberg, op. cit., p. 108. 
de socialistas y anarquistas, después de lo cual se realizaron algunas deportaciones.

La explosión de una bomba en ese mismo año, en un atentado atribuido a los anarquistas, sustentó la aprobación de la Ley de Defensa Social, mediante la cual se prohibía la entrada de anarquistas al país, se limitaban las reuniones y manifestaciones de los anarquistas residentes, se regulaba la manufactura y uso de explosivos y se establecían penas para quienes transportaran a Argentina a extranjeros indeseables. Esta ley había sido precedida en 1902 por la Ley de Residencia, que facultaba al ejecutivo a deportar sin juicio previo a los extranjeros acusados de perturbar el orden social; este precepto legal se concibió como un medio de defensa contra el número creciente de huelgas, cuyo origen residía, según la oligarquía, en la actividad disolvente de anarquistas de origen inmigratorio y no en las desigualdades sociales. ¡Ésta era la legislación que Lugones ensalzaba como uno de los fundamentos de la democracia!

La amenaza de la "plebe ultramarina" había crecido en 1912, cuando la llamada Ley Sáenz-Peña abrió la posibilidad del voto para las mayorías. El impulso a esta ley había provenido, dentro de la clase dominante, del ala reformista de la oligarquía, la que, quizá en un afán de conservar el control político sin provocar disturbios sociales, había creído en la posibilidad de legitimar su poderío mediante una mayor participación ciudadana. Sin embargo, la oligarquía nunca previó que esta ley podía significar su desalojo del poder político. Estamos en 1916, en vísperas de que el voto popular otorgue su apoyo al radicalismo de tendencia populista encabezado por Hipólito Yrigoyen.

Consecuente con su ideología, "Lugones inicia en este análisis del poema gauchesco el ataque al sistema de gobierno de las mayorías'”23. Así, la ambigua sanción del autor a la democracia expresada en sus conferencias de 1913, transcrita más arriba, se convierte en el prólogo de 1916, ante las amenazas del voto popular, en una franca y desembozada actitud antidemocrática: "La ralea mayoritaria paladeó un instante el quimérico pregusto de manchar [a] un escritor a quien nunca habían tentado las lujurias del sufragio universal" (p. 15).

Esta abierta postura antidemocrática de 1916 presagia la po-

${ }^{23}$ Gladys ONEGA, La inmigración en la literatura argentina (1880-1910), CEAL, Buenos Aires, 1982, p. 148. 
sición asumida en 1923 por Lugones ${ }^{24}$. Bajo los auspicios de la Liga Patriótica Argentina de Manuel Carlés, organización nacionalista de derecha dirigida a defender los intereses de la oligarquía y a atacar la democracia política y el movimiento obrero, y del Círculo Tradición Argentina, Lugones pronunció en ese año unas conferencias en donde dijo: "Nosotros hemos querido cumplir el mandato de nuestros padres, haciendo de esta Patria lo que debe ser: una gran concordia. A la discordia nos la han traído de afuera'"25. Según esta afirmación, el ideal de orden, que junto con el de progreso había conformado el lema del proyecto liberal, se veía frustrado por la acción disolvente de la anarquía, atribuida total y exclusivamente a la población de origen inmigratorio. Con esta visión, el inmigrante, que en el discurso de los pensadores del siglo xIx se consideraba como el instrumento indispensable para propiciar la civilización, pasa a ser el nuevo agente de la barbarie.

La frase "A la discordia nos la han traído de afuera", repetida con insistencia por Lugones, plantea la aguda lucha de clases argentina de principios de siglo como un conflicto entre nativos e inmigrantes, entre poseedores legítimos y advenedizos, y, más aún, mitifica el pasado argentino preinmigratorio como una sociedad sin contradicciones, como la "gran concordia". Para restablecer este estado, Lugones invoca la fuerza militar y la acción organizada de los civiles en contra de los movimientos anarquistas, en una propuesta fascista que él define como patriótica y nacional: "No hay guerra civil con extranjeros. Por el contrario: toda guerra con extranjeros es una guerra nacional"'26. Estamos ya en el militarismo descarado de Lugones, en la famosa "hora de la espada" del discurso que pronunció en Lima en 1924 durante la celebración del centenario de la batalla de Ayacucho. Todo ello preludia la función de ideólogo asumida por Lugones en el desarrollo del golpe militar del 6 de septiembre de 1930 mediante el cual Uriburu alcanzó el poder.

En el momento en que la invocación nostálgica y nacionalista del gaucho se muestra insuficiente para contener los embates del

${ }^{24}$ La trayectoria político-ideológica de Lugones se encuentra explicada con detalles en Marysa Navarro Gerassi, Los nacionalistas, trad. Alberto Ciria, Ed. Jorge Álvarez, Buenos Aires, 1968, pp. 37-45, así como en Nó́ JITRIǨ, Leopoldo Lugones, mito nacional, Palestra, Buenos Aires, 1960.

${ }^{25}$ Apud G. ONEGA, op. cit., p. 151.

${ }^{26}$ Loc. cit. 
creciente poder político y social de las masas inmigratorias contra la oligarquía, Lugones asume una posición más directa: su nacionalismo cultural deviene agresiva actitud política, no velada por el discurso literario, y su ideología reaccionaria queda totalmente al descubierto y no puede enmascararse más en mitos de dudosa validez "nacional".

Rafael Olea Franco

El Colegio de México 